\title{
SEOM clinical guidelines for the treatment of non-small cell lung cancer (NSCLC) 2015
}

\author{
R. García-Campelo ${ }^{1} \cdot$ R. Bernabé ${ }^{2} \cdot$ M. Cobo ${ }^{3} \cdot$ J. Corral $^{4}$. \\ J. Coves ${ }^{5} \cdot$ M. Dómine ${ }^{6} \cdot$ E. Nadal ${ }^{7} \cdot$ D. Rodriguez-Abreu ${ }^{8}$. \\ N. Viñolas ${ }^{9} \cdot$ B. Massuti ${ }^{10}$
}

Received: 10 November 2015/Accepted: 12 November 2015/Published online: 21 December 2015

(C) The Author(s) 2015. This article is published with open access at Springerlink.com

\begin{abstract}
Lung cancer is the most common cancer worldwide as well as the leading cause of cancer related deaths as reported by Torre et al (CA Cancer J Clin 65:87-108, 2015]. Non-small cell lung cancer (NSCLC) accounts for up to $85 \%$ of all lung cancers. Multiple advances in the staging, diagnostic procedures, therapeutic options, as well as molecular knowledge have been achieved during the past years, although the overall outlook has not greatly changed for the majority of patients with the overall 5-year survival having marginally increased over the last decade from 15.7 to $17.4 \%$ as reported by Howlader et al. (SEER Cancer Statistics Review 2015).
\end{abstract}

Keywords NSCLC $\cdot$ Radiotherapy · Chemotherapy · Targeted therapies

\section{Methodology}

Relevant studies published in peer review journals were used for the guideline elaboration. The Infectious Diseases Society of America grading system was used to

R. García-Campelo

maria.rosario.garcia.campelo@sergas.es

1 Medical Oncology Department, Complejo Hospitalario Universitario A Coruña, Coruña, Spain

2 Medical Oncology Department, Hospital Universitario Nstra. Sra. de Valme, Seville, Spain

3 Medical Oncology Department, Hospital Universitario Málaga, Málaga, Spain

4 Medical Oncology Department, Hospital Universitario Virgen del Rocío, Seville, Spain

5 Medical Oncology Department, Hospital Son Llatzer, Palma De Mallorca, Spain assign levels of evidence and grades of recommendation.

\section{Diagnosis}

Anatomopathological diagnosis of non-small cell lung cancer should be made according to the World Heath Organization (WHO) classification. The International Association for the Study of Lung Cancer (IASLC) provided adenocarcinoma classification as well as key recommendations for the management of small biopsies and cytology [3]. For therapeutic implications, specific subtyping of NSCLC is strongly recommended whenever possible. A limited diagnostic workup is also recommended to preserve as much tissue as possible for further molecular assessments. Evidence-based recommendations for molecular testing in lung cancer have been recently updated by SEOM-SEAP (Spanish Society of Medical Oncology-Spanish Society of Pathology) [4] (Table 3).

6 Hospital Universitario Fundación Jiménez Díaz. Oncohealth Institute, Madrid, Spain

7 Medical Oncology Department, Instituto Catalán de Oncología, L'Hospitalet, Barcelona, Spain

8 Medical Oncology Department, Hospital Universitario Insular de Las Palmas de Gran Canaria, Las Palmas, Spain

9 Medical Oncology Department, Hospital Clinic I Provincial de Barcelona, Barcelona, Spain

10 Medical Oncology Department, Hospital General Universitario Alicante, Alicante, Spain 


\section{Staging}

In NSCLC the following staging work-up is highly recommended:

- Clinical history, including smoking and family history; physical examination, performance status (PS) and weight loss should be assessed.

- Blood test, including hematology, renal and hepatic function.

- Chest and upper abdomen (including liver and adrenal glands) computerized tomography (CT).

- Brain CT or magnetic resonance imaging (MRI) if there are neurological symptoms in the physical examination.

- Bone scan if there is bone pain, high serum calcium or high alkaline phosphatase.

In patients undergoing potentially radical treatment, the following recommendations should be considered:

- Whole-body FDG-positron emission tomography (PET)-CT

- Bronchoscopy

- Pulmonary function tests

- Ergospirometry if the pulmonary function tests are not normal

- Chest MRI in Pancoast tumour

- Invasive mediastinal staging, endobronchial ultrasound-guided fine-needle aspiration (EBUS-FNA), and/or endoscopic ultrasound guided fine-needle aspiration (EUS-FNA), is recommended in patients with PET positive mediastinal or hilar lymph nodes (LNs). For patients with suspect LNs on imaging and negative EBUS/EUS results, an additional mediastinoscopy is recommended. In patients with PET-negative LNs,

Table 1 Staging Grouping (Adapted from Goldstraw et al. [5])

\begin{tabular}{llll}
\hline Occult carcinoma & TX & N0 & M0 \\
\hline Stage 0 & Tis & N0 & M0 \\
Stage IA & T1a, b & N0 & M0 \\
Stage IB & T2a & N0 & M0 \\
Stage IIA & T1a,b & N1 & M0 \\
& T2a & N1 & \\
Stage IIB & T2b & N0 & \\
Stage IIIA & T2b & N1 & \\
& T3 & N0 & \\
Stage IIIb & T1,T2 & N2 & \\
Stage IV & T3 & N1,N2 & \\
\hline
\end{tabular}

invasive staging is also recommended in CT enlarged mediastinal LNs $(>1.5 \mathrm{~cm})$ and in patients with central tumours.

- Histological and cytological confirmation is strongly recommended in the presence of pleural/pericardial effusion or isolated metastatic site.

\section{Staging system}

NSCLC is staged according to the UICC system (7th edition), grouped into stage categories (Tables 1 and 2) [5]. The 7 th edition is recommended until the 8 th will be approved in 2016.

\section{Treatment}

\section{Stage I-II}

Patients with clinically stage I-II NSCLC should be evaluated in a multidisciplinary tumor board and a preoperative pulmonary assessment is recommended to identify patients at increased risk of post-operative complications following lung cancer.

\section{Surgery}

Surgical resection is the treatment of choice for patients with early-stage NSCLC, and yields the best potential cure rate in patients with stage I-II and no medical contraindications to operative intervention (IB).

The surgical resection used will depend on the extent of the disease, the location of the tumor and the cardiopulmonary reserve of the patient:

- In stage I-II NSCLC patients who are medically fit for surgery, a lobectomy or anatomic pulmonary resection is recommended rather than a sublobar resection (IB) [6]. Systematic mediastinal lymph node sampling or dissection at the time of anatomic resection is also recommended for accurate staging over selective or no sampling [7] (IB).

- A sublobar resection (segmentectomy or a non-anatomical wedge resection) is recommended for those patients who cannot tolerate a lobectomy due to comorbidities or decreased pulmonary function (IB).

- A sublobar resection with negative margins can be considered for patients with small peripheral nodules $(\leq 1 \mathrm{~cm})$ with a predominantly ground glass opacity (IB).

- In central tumors, a sleeve lobectomy is the preferred type of resection over a pneumonectomy (IIC).

- Re-resection is recommended for patients with positive margins in resected stage I-II NSCLC. If re-resection is 
Table 2 TNM classification $7^{\mathrm{a}}$ edition (Adapted from Goldstraw et al. [5])



not possible, postoperative radiotherapy (PORT) should be considered [8].

\section{Adjuvant therapy}

The beneficial effect in terms of survival of adjuvant cisplatin based chemotherapy in completely resected fit stage II-III NSCLC patients is now well established [9].

- For patients with completely resected stage II NSCLC, four cycles of postoperative platinum-based chemotherapy are recommended (IA).

- Postoperative chemotherapy is not recommended for patients with completely resected stage IA NSCLC (IB) and its use remains controversial in patients with large IB tumors $(\geq 4 \mathrm{~cm})$ (IC).

- In elderly fit patients ( $\leq 80$ years), postoperative platinum-based chemotherapy should be considered as well.
PORT is not recommended for patients with completely resected stage I-II NSCLC (IA and IIA, respectively) [10].

\section{Stereotactic radiotherapy $(S B R T)$}

SBRT is recommended for patients with node negative tumors $\leq 5 \mathrm{~cm}$ who are deemed medically inoperable or who decline surgery (IIC). Several non-randomized studies suggested that this technique might be a suitable option for operable patients older than 75 years (IIC).

Targeted agents are not recommended in the postoperative setting. Adjuvant erlotinib did not improve diseasefree survival in patients with EGFR-expressing NSCLC or in the EGFR mutant subgroup [11]. Several trials are currently testing the use of targeted therapies in patients with resected $E G F R / A L K$ positive NSCLC. 


\section{Stage III}

Stage III NSCLC represents a heterogeneous group of patients with presentations that range from resectable tumors to unresectable ones. Due to the complexity of most stage III disease presentations, treatment decision must be made within an expert multidisciplinary team management (Fig. 1).

Stage III has been classified into different subgroups:

- In patients with R0 resected NSCLC and an incidental $\mathrm{N} 2$ metastases found on final pathology examination of the resection specimen, adjuvant chemotherapy should be given [8] (IA). PORT may be considered (IVC) and should be administered after adjuvant chemotherapy. Retrospective analyses from randomized trials suggest a potential benefit of adjuvant radiotherapy in N2 disease. There is an ongoing European trial (LungART) evaluating this strategy.

- In patients with $\mathrm{N} 2$ documented intra-operatively, surgery should be followed by adjuvant chemotherapy (IA) +/- PORT (IVC).

- In potentially resectable IIIA (N2), several randomized clinical trials have compared the outcome of primary surgery versus neoadjuvant therapy followed by surgery with fairly consistent trend to better survival for combined treatment. The Cochrane meta-analysis demonstrated that preoperative therapy is better than surgery alone for patients with stage III [12]. There are also several trials that have evaluated the role of surgery after preoperative therapy compared with a nonsurgical curative-intent strategy obtaining similar results. The North American intergroup 0139 study showed better progression-free survival (PFS) but no survival except in the unplanned subgroup patients who underwent lobectomy [13]. The optimal chemotherapy regimen has not been investigated in randomized

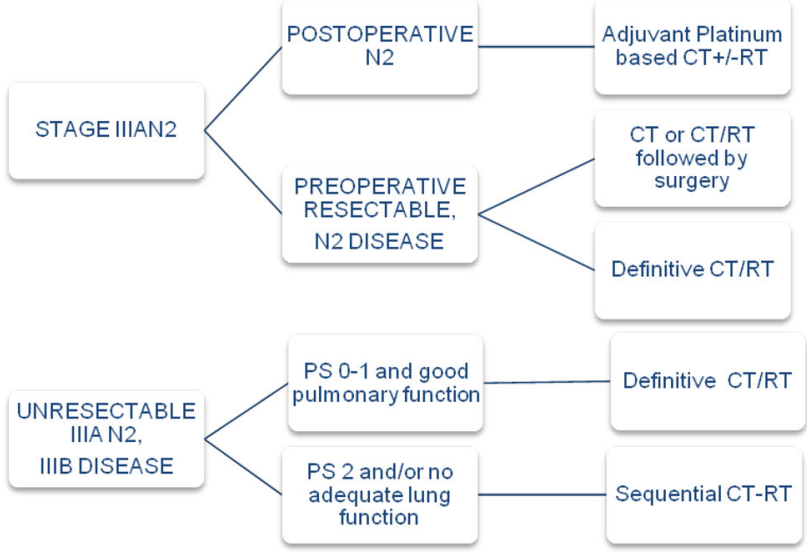

Fig. 1 Treatment algorithm for Stage III studies, but cisplatin-based chemotherapy is recommended. These patients could be treated with induction chemotherapy followed by surgery, induction chemoradiotherapy followed by surgery or concurrent definitive chemoradiotherapy (IA). Trimodality treatment is preferably planned in patients in whom a complete resection by lobectomy is expected.

- In unresectable IIIA (N2) (bulky and multiple mediastinal nodal involvement) and IIIB disease, PS 0-1 and minimal weight loss, concurrent chemoradiotherapy is the treatment of choice (IA). Several phase III trials and a meta-analysis based on individual patient data have showed an overall survival (OS) benefit of $4.5 \%$ at 5 years [14]. For fit patients with inoperable stage III, 2-4 cycles of cisplatin-based chemotherapy is recommended (IA), being etoposide and vinorelbine platinum combinations the most commonly used. There is no evidence for induction or consolidation treatment.

- If concurrent chemoradiotherapy is not possible, induction chemotherapy followed by definitive radiotherapy is an effective alternative [15] (IA).

- Radiotherapy dose of 60-66 Gy in 30-33 daily fractions of $1.8-2 \mathrm{~Gy}$ is recommended for concurrent chemoradiotherapy. The RTOG 0617 study has demonstrated that radiation dose of $74 \mathrm{~Gy}$ is not superior to the standard dose [16] (IA).

There is no role for prophylactic cranial irradiation in stage III [17] (IIA).

There is currently no role for targeted agents in the treatment of stage III [18] (IA).

\section{Stage IV (Fig. 2)}

\section{First line therapy}

For stage IV PS 0-1 NSCLC patients, without driver mutations, a combination of cytotoxic chemotherapy is recommended, based on tumor histology (IA). Early palliative care is strongly recommended (Fig. 2).

\section{For squamous cell lung cancer (SCC)}

- Two drugs platinum based combination must be offered. Data have shown that platinum combination therapy increases OS and improves QoL compared to supportive care [19] (IA). None of the cisplatin or carboplatin regimens with third generation drugs have shown clear superiority over others in the treatment of SCC. The choice of the combination must take into account the toxicity profile and patient comorbidities (IA).

- Although cisplatin and carboplatin have demonstrated similar activity, a meta-analysis has reported higher response rate (RR) and significantly OS increase in 


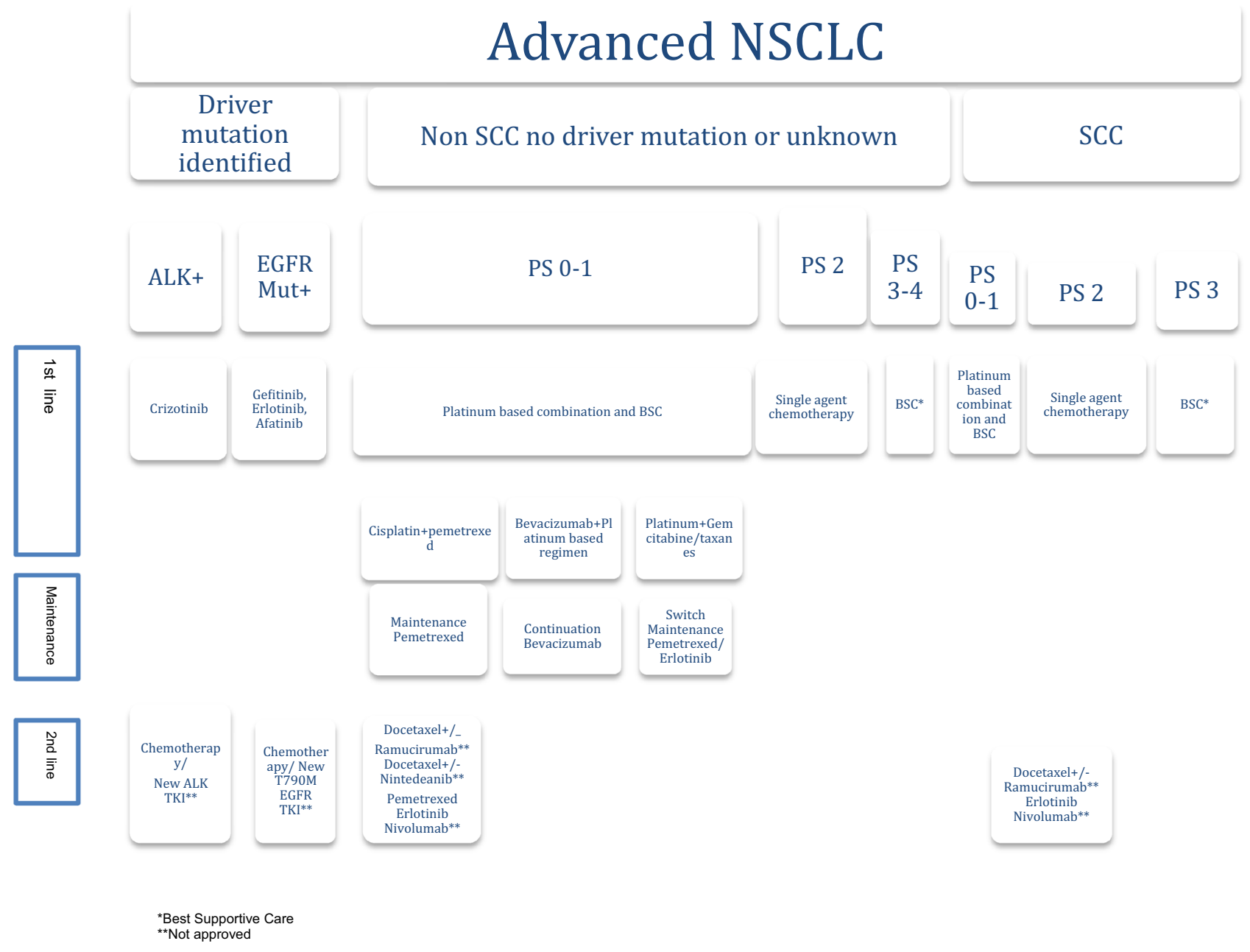

Fig. 2 Treatment algorithm for Stage IV

patients treated with cisplatin [20]. Carboplatin can be recommended if any contraindications for cisplatin exist (IA).

- The non-platinum regimens have reported lower activity as compared to platinum regimens [21] (IB).

- Four, up to a maximum of six cycles in selected cases, are recommended [22] (IA).

\section{For non-squamous cell lung cancer (Non-SCC)}

- Platinum-doublet combination is also recommended. Cisplatin/pemetrexed demonstrated more efficacy and less toxicity compared to cisplatin/gemcitabine [23] (IA). If any contraindications for cisplatin exist or in elderly fit patients, the combination pemetrexed/carboplatin could be a valuable treatment option [24] (IB).
- Bevacizumab can be added to the first line treatment in combination with platinum regimens in patients with PS $0-1$ and without any specific contraindication for antiangiogenic therapy (IA). Bevacizumab must continue to be administered until disease progression or toxicity [25].

- Non-platinum combinations can be considered in some cases.

- Chemotherapy should be continued for a total of 4-6 cycles in selected cases.

- Maintenance therapy can be considered in those PS 0-1 patients who achieve at least stabilization and have recovered from toxicities from the previous induction therapy (IA):

- Pemetrexed and erlotinib can be used as switch maintenance after four cycles of platinum-base induction chemotherapy [26, 27] (IIB). 
- Pemetrexed is also indicated in continuation maintenance after four induction cycles of platinum/pemetrexed [28] (IA).

- Maintenance should be administered until unacceptable toxicity or disease progression.

Elderly and PS2:

- Elderly fit patients with PS 0-1 should be treated with platinum combination chemotherapy according to histology [29] (IA).

- Patients with important comorbidities or PS2 are suitable for being treated with monotherapy regimen.

- Unfit PS 3-4 patients, should not receive chemotherapy regardless of age, and supportive care must be recommended. However, patients with EGFR mutations or $A L K$ rearrangements may also be offered an $E G F R$ or $A L K$ TKI (IIA).

Solitary metastases Patients with limited disease in chest and unique metastasis site (mainly solitary brain or adrenal metastasis) may benefit from an aggressive local therapy approach (RT, surgery or SBRT) both in the primary and metastatic site [30] (IIIA).

\section{Second and third line}

- Patients clinically or radiologically progressing after first-line chemotherapy, PS 0-1 should be offered second-line treatment (IA).

- Docetaxel, erlotinib, or pemetrexed (only in non-SCC) have demonstrated improvement in terms of OS and QoL [31-33] (IA).

- Combination regimens have failed to show any survival benefit over single agents with more toxicity [34] (IA).

- Erlotinib may be recommended as third-line therapy for patients with PS of 0-2 who have not received prior EGFR TKIs (IA).

- Recently, novel therapeutic strategies have demonstrated significant benefit in OS in the second line setting, but they have not been approved yet by the Spanish Agency of Drugs and Sanitary Products (AEMPS):

- The addition of ramucirumab [35] (monoclonal antibody against VEGFR-2) to docetaxel, demonstrated a significant OS benefit compared to docetaxel alone in previously treated PS 0-1 NSCLC patients.

- Nintedanib [36] (VEGFR 1-3, FGFR 1-3, PDGFR alpha/beta and RET TKI) added to docetaxel has demonstrated a significant OS benefit as compared with docetaxel alone in previously treated stage IV, PS 0-1 adenocarcinoma.

- Nivolumab, PD-1 monoclonal antibody, improves the RR and the OS as compared with docetaxel alone in previously treated SCC NSCLC independently of the $P D-L 1$ expression [37]. Preliminarily, Nivolumab resulted no survival inferior to docetaxel in the non-SCC population, but improved overall RR and OS in patients with $P D-L 1$ overexpression [38].

\section{Targeted therapy for stage IV NSCLC}

Significant advances in understanding the molecular biology of NSCLC led to the identification of driver alterations and novel therapeutic targets. The majority of these alterations occur in adenocarcinomas although potential targets in SCC are also emerging. Drugs targeting the EGFR and $A L K$ genes, respectively, are currently approved. Testing for both alterations is recommended upfront in stage IV non-SCC regardless of clinical characteristics, and in nonsmokers irrespective of histology (IA).

\section{EGFR mutation}

The frequency of EGFR mutations in Spanish population is around $10-16 \%$ of patients. The most commonly found EGFR mutations are the exon 19 deletions (Del19) and the exon 21 L858R point mutation (85-90\%).

First-line patients harboring EGFR mutations should be treated with an EGFR TKI (Gefitinib, Erlotinib, Afatinib) (IA). Consistent evidence of several phase III trials have showed superior PFS, RR, toxicity profiles and QoL for EGFR TKIs compared with platinum-based doublets [3941]. These studies did not show statically significant differences in OS, although a prespecified sub-analysis of LUX-Lung 3 and 6 trials showed a significant improvement in OS favoring afatinib vs chemotherapy in Del19 patients [42]. The results from direct comparative trials among different EGFR TKIs are not yet available, although ongoing randomized trials, comparing first generation with second and third generation EGFR TKIs are awaited.

For patients with stage IV NSCLC harboring EGFR mutations that progressed to first line therapy:

- Rebiopsy is at the time of progression in patients with $E G F R$ mutations treated with first- or second-generation EGFR TKIs at front line, and benefits/risks should be discussed with the patient (IIIC). 
- An EGFR TKI should be recommended if not received during the first line setting (IA).

- Platinum-based chemotherapy can be recommended after progression to an EGFR TKI (IIA).

- $\quad E G F R$ T790M gatekeeper mutation is considered to be the main mechanism of acquired resistance to EGFR TKIs. Third generation EGFR TKIs such as AZ9291, Rociletinib, HM61713, EGF 816 or ASP 8273 are selective for $\mathrm{T} 790 \mathrm{M}$ resistance mutation and have shown significant activity in several phase I and II trials in patients with acquired resistance to first and second generation EGFR TKIs. Results from ongoing clinical trials are awaited to recommend these drugs in the second line setting.

- Continuing EGFR TKI in combination with platinumbased chemotherapy beyond progression has failed to demonstrate a significant benefit and should not be recommended [43].

\section{ALK gene rearrangement}

$A L K$ rearrangements, mainly translocations, occur in around $4 \%$ of NSCLC.

- For those $A L K$ positive patients, Crizotinib should be recommended in the first line setting (IA). The phase III trial PROFILE 1014, compared crizotinib vs platinum-pemetrexed confirming a significant benefit in terms of PFS, RR and QoL [44].

- If not received during the first line setting, Crizotinib should be recommended as second-line treatment (IA). The recommendation is based on the phase III trial PROFILE 1007, that compared crizotinib vs chemotherapy (either pemetrexed or docetaxel) in patients with locally advanced or metastatic $A L K$ positive NSCLC previously treated. Crizotinib achieved significant better outcome in terms of PFS, RR, toxicity profile and QoL [45].

- For those patients progressing on Crizotinib treatment, Ceritinib, a second generation $A L K$ TKI has received the approval from the FDA and EMA on the basis of a phase I single-arm trial obtaining a RR of $56 \%$ and mPFS of 6.9 months [46] (IIB).

- Chemotherapy may still be appropriate in the absence of phase III data comparing ceritinib with chemotherapy. The chemotherapy regimens are the same as were recommended as first-line using platinum-based combinations (IA).

- Other $A L K$ inhibitors under investigation include alectinib, brigatinib and lorlatinib have been reported to have high activity in $A L K$ positive patients including patients with brain metastases. Results from ongoing clinical trials evaluating new $A L K$ TKIs are awaited.

\section{Other targetable genetic alterations}

The prevalence of other molecular alterations with potentially actionable drugs is low $(<2 \%)$. None of these targeted drugs has regulatory approval. Routine testing for these biomarkers is not currently recommended (IIIC).

Early clinical trials have shown the activity of targeting drugs as crizotinib (ROS1 fusion and MET amplification), vemurafenib and dabrafenib or dabrafenib plus trametinib (BRAF mutations), anti-HER2 monoclonal antibodies or HER2 TKIs (HER2 mutations) and other potential drugs targeting RET fusion, PI3 $\mathrm{K}$ mutations and others. However, no active agent has been clinically proven yet in KRAS mutations. Available evidence for the use of these agents is limited based in early clinical trials (Table 3 ).

\section{Follow-up}

Follow-up frequency in patients with NSCLC is a controversial issue.

After curative-intent

- In patients who have had surgery, follow-up visit including history, physical examination and spiral chest CT is recommended every 6-12 months for the first 2 years and annually thereafter (IIIB).

- For patients who have undergone curative-intent therapy, routine surveillance with blood test, PET imaging or another radiological assessment is not recommended (IID).

- For patients treated with SBRT, CT scans every 6 months for 3 years are recommended if patients are suitable for salvage treatment (IIIB). The use of FDGPET (and biopsy if positive) is recommended when recurrence after SBRT is suspected based on chest CT (IIIB).

In advanced disease patients:

- Treatment response is recommended to be evaluated 9 or 12 weeks after treatment begins, using the same radiographic method used at baseline. Depending on individual clinical judgement, a repeat scan might be performed after 6 weeks.

- For patients eligible for active cancer therapy in successive lines of treatment, it is advisable to undergo 
Table 3 Summary of recommendations

Recommendations

\section{Diagnosis}

\section{Stage I-II}

Patients medically fit for surgery

Patients medically inoperable, node negative,

tumors $<5 \mathrm{~cm}$

Post-operative radiotherapy (PORT)

Adjuvant chemotherapy (four cycles of adjuvant cisplatinbased chemotherapy

\section{Targeted agents}

\section{Stage III}

Postoperative IIIA (N2)

Preoperative resectable IIIA (N2)

Unresectable IIIA (N2), IIIB

\section{Stage IV without driver mutations}

First line setting

For PS 0-1, platinum-based doublets are recommended based on tumor histology

Non-SCC

SCC

Elderly

PS $0-2$

Maintenance

Second line setting and beyond

\section{Stage IV EGFR Mut NSCLC}

First-line stage IV EGFR Mut NSCLC

Platinum-based doublet

Cisplatin/pemetrexed doublet has demonstrated more efficacy and less toxicity compared to cisplatin/gemcitabine

Bevacizumab added to a platinum doublet if there are no contraindications. Bevacizumab must continue to be administered until disease progression or toxicity

Platinum-based doublet

Elderly fit patients with PS 0-1 should be treated with platinum combination chemotherapy according to histology

Patients with important comorbidities or PS2 are suitable for being treated with monotherapy regimen

For PS 0-1, non-SCC patients with stable disease or response after four cycles

Pemetrexed or erlotinib can be used as switch maintenance

Pemetrexed is also indicated in continuation maintenance after four induction cycles of platinum/pemetrexed

For PS 0-2, docetaxel, erlotinib, or pemetrexed (only in non-SCC)

Erlotinib may be recommended as third-line therapy for patients with PS of 0-2 who have not received prior EGFR TKIs

Gefitinib, erlotinib, afatinib

EGFR Mut patients who have not received and EGFR TKI Gefitinib, erlotinib, afatinib as first line 
Table 3 continued

Recommendations

EGFR Mut patients who progressed after first-line treatment with an EGFR TKI

Platinum-based chemotherapy

Stage IV $A L K$ rearranged NSCLC

First-line ALK-rearranged stage IV NSCLC Crizotinib

Second line $A L K$-rearranged naive patients Crizotinib

Crizotinib-naive $A L K$-rearranged NSCLC patients who have Crizotinib received one prior platinum-based regimen

$A L K$-rearranged NSCLC patients who have received Chemotherapy previously crizotinib

Ceritinib*

\section{Other genetic alterations}

$\begin{array}{ll}\text { Ros } 1 & \text { Crizotinib* (IIC) } \\ \text { Met } \text { amplification } & \text { Crizotinib* (IVC) } \\ \text { BRAF mut } & \text { Vemurafenib*, Dabrafenib* (IVC) } \\ & \text { Dabrafenib* + Trametinib* (IIIC) } \\ \text { Her2 mut } & \text { Her2 monoclonal antibodies*, Her2 TKIs* (IVC) }\end{array}$

* Not approved

clinical and/or radiological evaluation 6 weeks after finishing treatment and then every 6-12 weeks to enable second-line therapy to commence promptly (IIIB).

\section{Compliance with ethical standards}

Conflict of interest The authors declare that they have no conflict of interest.

Open Access This article is distributed under the terms of the Creative Commons Attribution 4.0 International License (http://crea tivecommons.org/licenses/by/4.0/), which permits unrestricted use, distribution, and reproduction in any medium, provided you give appropriate credit to the original author(s) and the source, provide a link to the Creative Commons license, and indicate if changes were made.

\section{References}

1. Torre LA, Bray F, Siegel RL. Global cancer statistics, 2012. CA Cancer J Clin. 2015;65(2):87-108.

2. Howlader N, Noone AM, Krapcho M, Garshell J, Miller D, Altekruse SF, et al. SEER Cancer Statistics Review, 1975-2012. Bethesda: National Cancer Institute; 2015.

3. Lindeman NI, Cagle PT, Beasley MB, Chitale DA, Dacic S, Giaccone G, et al. Molecular testing guideline for selection of lung cancer patients for EGFR and ALK tyrosine kinase inhibitors: guideline from the College of American Pathologists, International Association for the Study of Lung Cancer, and Association for Molecular Pathology. J Thorac Oncol. 2013;8:823-59.

4. Felip E, Concha A, de Castro J, Gómez-Román J, Garrido P, Ramírez J, et al. Biomarker testing in advanced non-small-cell lung cancer: a National Consensus of the Spanish Society of Pathology and the Spanish Society of Medical Oncology. Clin Transl Oncol. 2015;17(2):103-12.

5. Rami-porta R, Crowley JJ, Goldstraw P. The revised TNM system for lung cancer. Ann Thorac Cardiovasc Surg. 2009;15(1):4-9.

6. Ginsberg RJ, Rubinstein LV. Randomized trial of lobectomy versus limited resection for T1 N0 non-small cell lung cancer. Lung Cancer Study Group. Ann Thorac Surg. 1995; 60:615-22.
7. El-Sherif A, Gooding WE, Santos R, Pettiford B, Ferson PF, Fernando HC, et al. Outcomes of sublobar resection versus lobectomy for Stage I non-small cell lung cancer: a 13-year analysis. Ann Thorac Surg. 2006;82:408-16.

8. Wang EH, Corso CD, Rutter CE, Park HS, Chen AB, Kim AW, et al. Postoperative radiation therapy is associated with improved overall survival in incompletely resected stage II and III non-small-cell lung cancer. J Clin Oncol. 2015;33(25):2727-34.

9. Pignon J-P, Tribodet H, Scagliotti GV, Douillard JY, Shepherd FA, Stephens RJ, et al. Lung adjuvant cisplatin evaluation: a pooled analysis by the LACE Collaborative Group. J Clin Oncol. 2008;26:3552-9.

10. Burdett S, Stewart L. Postoperative radiotherapy in non-small-cell lung cancer: update of an individual patient data meta-analysis. Lung Cancer. 2005;47:81-3.

11. Kelly K, Altorki NK, Eberhardt WE, O’Brien ME, Spigel DR, Crinò L, et al. Adjuvant erlotinib versus placebo in patients with stage IB-IIIA non-small-cell lung cancer (RADIANT): a randomized, doubled-blind, phase III trial. J Clin Oncol. 2015 pii: JCO.2015.61.8918. [Epub ahead of print].

12. Burdett SS, Stewart LA, Rydzewska L. Chemotherapy and surgery versus surgery alone in non-small cell lung cancer. Cochrane Database Syst Rev. 2007;3:CD006157.

13. Albain KS, Swann RS, Rusch VW, Turrisi AT 3rd, Shepherd FA, Smith C, et al. Radiotherapy plus chemotherapy with or without surgical resection for stage III non small cell lung cancer: a phase III randomized controlled trial. Lancet. 2009;374:379-86.

14. Auperin A, le Pechoux C, Rolland E, Curran WJ, Furuse K, Fournel P, et al. Meta-analysis of concomitant versus sequential radiochemotherapy in locally advanced non-small cell lung cancer. J Clin Oncol. 2010;28:2181-90.

15. Pritchard RS, Anthony SP. Chemotherapy plus radiotherapy compared with radiotherapy alone in the treatment of locally advanced, unresectable, nonsmall-cell lung cancer. A meta analysis. Ann Intern Med. 1996;125(9):723-9.

16. Bradley JD, Paulus R, Komaki R, Masters G, Blumenschein G, Schild S, et al. Standard-dose versus high-dose conformal radiotherapy with concurrent and consolidation carboplatin plus placitaxel with or without cetuximab for patients with stage IIIA or IIIB non-small-cell lung cancer (RTOG0167): a randomized, two-by-two factorial phase 3 study. Lancet Oncol. 2015;16:187-99.

17. Gore EM, Bae K, Wong SJ, Sun A, Bonner JA, Schild SE, et al. Phase III comparison of prophylactic cranial irradiation versus observation in patients with locally advanced non-small-cell lung cancer: primary analysis of Radiation Therapy Oncology Group study RTOG 0214. J Clin Oncol. 2011;29:272-8.

18. Kelly K, Chansky KI, Gaspar LE, Albain KS, Jett J, Ung Y-C, et al. Phase III trial of maintenance gefitinib or placebo after concurrent chemoradiotherapy and docetaxel consolidation in inoperable stage III non-small-cell lung cancer. SWOGS0023. J Clin Oncol. 2008;26:2450-6.

19. Schiller JH, Harrington D, Belani CP, Langer C, Sandler A, Krook J, et al. Comparison of four chemotherapy regimens for advanced non-small-cell lung cancer. N Engl J Med. 2002;346(2):92-8.

20. Ardizzoni A, Boni L, Tiseo M, Fossella FV, Schiller JH, Paesmans M, et al. Cisplatin-versus carboplatin-based chemotherapy in first-line treatment of advanced non-small-cell lung cancer: an individual patient data meta-analysis. J Natl Cancer Inst. 2007;99:847-57. 
21. D'Addario G, Pintilie M, Leighl NB, Feld R, Cerny T, Shepherd FA. Platinumbased versus non-platinum-based chemotherapy in advanced non-small-cell lung cancer: a meta-analysis of the published literature. J Clin Oncol. 2005;23(13):2926-36.

22. Rossi A, Chiodini P, Sun JM, O'Brien ME, von Plessen C, Barata F, et al. Six versus fewer planned cycles of first-line platinum-based chemotherapy for nonsmall-cell lung cancer: a systematic review and meta-analysis of individual patient data. Lancet Oncol. 2014;15(11):1254-62.

23. Scagliotti GV, Parikh P, von Pawel J, Biesma B, Vansteenkiste J, Manegold C, et al. Phase III study comparing cisplatin plus gemcitabine with cisplatin plus pemetrexed in chemotherapy-naive patients with advanced-stage NSCLC. J Clin Oncol. 2008;26:3543-51.

24. Gervais R, Robinet G, Clément-Duchêne C, Denis F, El Kouri C, Martin P, et al. Pemetrexed and carboplatin, an active option in first-line treatment of elderly patients with advanced non-small cell lung cancer (NSCLC): a phase II trial. Lung Cancer. 2013;80(2):185-90.

25. Soria JC, Mauguen A, Reck M, Sandler AB, Saijo N, Johnson DH, et al. Systematic review and meta-analysis of randomised, phase II/III trials adding bevacizumab to platinum-based chemotherapy as first-line treatment in patients with advanced non-small-cell lung cancer. Ann Oncol. 2013;24:20-30.

26. Ciuleanu T, Brodowicz T, Zielinski C, Kim JH, Krzakowski M, Laack E, et al. Maintenance pemetrexed plus best supportive care versus placebo plus best supportive care for non-small-cell lung cancer: a randomised, double-blind, phase 3 study. Lancet. 2009;374:1432-40.

27. Cappuzzo F, Ciuleanu T, Stelmakh L, Cicenas S, Szczésna A, Juhász E, et al. Erlotinib as maintenance treatment in advanced non-small-cell lung cancer: a multicentre, randomised, placebo-controlled phase 3 study. Lancet Oncol. 2010;11:521-9.

28. Paz-Ares LG, de Marinis F, Dediu M, Thomas M, Pujol JL, Bidoli P, et al. PARAMOUNT: final overall survival results of the phase III study of maintenance pemetrexed versus placebo immediately after induction treatment with pemetrexed plus cisplatin for advanced nonsquamous non-small-cell lung cancer. J Clin Oncol. 2013;31(23):2895-902.

29. Quoix E, Zalcman G, Oster JP, Westeel V, Pichon E, Lavolé A, et al. Carboplatin and weekly paclitaxel doublet chemotherapy compared with monotherapy in elderly patients with advanced non-small-cell lung cancer: IFCT-0501 randomised, phase 3 trial. Lancet. 2011;378:1079-88.

30. Ashworth AB, Senan S, Palma DA, Riquet M, Ahn YC, Ricardi U, et al. An individual patient data metaanalysis of outcomes and prognostic factors after treatment of oligometastatic non-small-cell lung cancer. Clin Lung Cancer. 2014; 15(5):346-55

31. Shepherd FA, Dancey J, Ramlau R, Mattson K, Gralla R, O'Rourke M, et al. Prospective randomized trial of Docetaxel versus best supportive care in patients with non-small-cell lung cancer previously treated with platinum-based chemotherapy. J Clin Oncol. 2000;18:2095-103.

32. Shepherd FS, Rodrigues Pereira J, Ciuleanu T, Tan EH, Hirsh V, Thongprasert $\mathrm{S}$, et al. Erlotinib in previously treated non-small-cell lung cancer. N Engl J Med. 2005;353:123-32

33. Hanna N, Shepherd FA, Fossella FV, Pereira JR, De Marinis F, von Pawel J, et al. Randomized phase III trial of pemetrexed versus docetaxel in patients with non-small-cell lung cancer previously treated with chemotherapy. J Clin Oncol. 2004;22:1589-97.

34. Di Maio M, Chiodini P, Georgoulias V, Hatzidaki D, Takeda K, Wachters FM, et al. Meta-analysis of single-agent chemotherapy compared with combination chemotherapy as second-line treatment of advanced non-small-cell lung cancer. J Clin Oncol. 2009;27:1836-43.

35. Garon EB, Ciuleanu TE, Arrieta O, Prabhash K, Syrigos KN, Goksel T, et al. Ramucirumab plus docetaxel versus placebo plus docetaxel for second-line treatment of stage IV non-small-cell lung cancer after disease progression on platinum-based therapy (REVEL): a multicentre, double-blind, randomised phase 3 trial. Lancet. 2014;384(9944):665-73.

36. Reck M, Kaiser R, Mellemgaard A, Douillard JY, Orlov S, Krzakowski M, et al. Docetaxel plus nintedanib versus docetaxel plus placebo in patients with previously treated non-small-cell lung cancer (Lume-Lung 1): a phase 3, doubleblind, randomised controlled trial. Lancet Oncol. 2014;15(2):143-55.

37. Brahmer J, Reckamp KL, Baas P, Crinò L, Eberhardt WE, Poddubskaya E, et al Nivolumab versus docetaxel in advanced squamous-cell non-small-cell lung cancer. N Engl J Med. 2015;373:123-35.

38. Borghaei H, Paz-Ares L, Horn L, Spigel DR, Steins M, Ready NE, et al Nivolumab versus docetaxel in advanced nonsquamous non-small-cell lung cancer. N Engl J Med. 2015;373(17):1627-39.

39. Mok TS, Wu YL, Thongprasert S, Yang CH, Chu DT, Saijo N, et al. Gefitinib or carboplatin-paclitaxel in pulmonary adenocarcinoma. $\mathrm{N}$ Engl $\mathrm{J}$ Med. 2009;361:947-57.

40. Rosell R, Carcereny E, Gervais R, Vergnenegre A, Massuti B, Felip E, et al. Erlotinib versus standard chemotherapy as first-line treatment for European patients with advanced EGFR mutation-positive non-small-cell lung cancer (EURTAC): a multicentre, open-label, randomised phase 3 trial. Lancet Oncol. 2012;13:239-46.

41. Sequist LV, Yang JC, Yamamoto N, O'Byrne K, Hirsh V, Mok T, et al. Phase III study of afatinib or cisplatin plus pemetrexed in patients with metastatic lung adenocarcinoma with EGFR mutations. J Clin Oncol. 2013;31:3327-34.

42. Yang JC, Wu YL, Schuler M, Sebastian M, Popat S, Yamamoto N, et al Afatinib versus cisplatin-based chemotherapy for EGFR mutation-positive lung adenocarcinoma (LUX-Lung 3 and LUX-Lung 6): analysis of overall survival data from two randomised, phase 3 trials. Lancet Oncol. 2015;16:141-51.

43. Soria JC, Wu YL, Nakagawa K, Kim SW, Yang JJ, Ahn MJ, et al. Gefitinib plus chemotherapy versus placebo plus chemotherapy in EGFR-mutation-positive non-small-cell lung cancer after progression on first-line gefitinib (IMPRESS): a phase 3 randomised trial. Lancet Oncol. 2015;16:990-8.

44. Solomon BJ, Mok T, Kim DW, Wu YL, Nakagawa K, Mekhail T, et al. Firstline crizotinib versus chemotherapy in ALK-positive lung cancer. N Engl J Med 2014;371:2167-77.

45. Shaw AT, Kim DW, Nakagawa K, Seto T, Crinó L, Ahn MJ, et al. Crizotinib versus chemotherapy in advanced ALK-positive lung cancer. N Engl J Med. 2013;368:2385-94.

46. Shaw AT, Kim DW, Mehra R, Tan DS, Felip E, Chow LQ, et al. Ceritinib in ALK-rearranged non-small-cell lung cancer. N Engl J Med. 2014;370:1189-97. 